\title{
Obituario: Teodoro Hampe Martínez (1960-2016): LAS BIBLIOTECAS VIRREINALES, LA REBELIÓN DEL CUSCO Y el Perú republicano
}

\begin{abstract}
Soledad González Díaz ${ }^{1}$
Germán Morong Reyes ${ }^{2}$

Patricio Ibarra Cifuentes ${ }^{3}$
\end{abstract}

El pasado domingo 7 de febrero de 2016 falleció en Lima, Perú, Teodoro Hampe Martínez. Su prematura partida, a los 56 años de edad, dejó a medio camino una prolífica carrera académica, a lo largo de la cual escribió más de veinte libros y múltiples capítulos de libros y artículos, todos caracterizados por una prosa erudita y, a la vez, accesible para el público no especialista. Esta preocupación por la difusión del conocimiento lo convirtió también en autor de un buen número de columnas y artículos en diarios y revistas, a los que se suman varias entrevistas en noticiarios y programas de televisión. Recordándolo desde Chile, en esta oportunidad nos gustaría dar cuenta de la contribución que Teodoro Hampe Martínez hizo a los estudios históricos centrados en el Perú, tanto virreinal como republicano, temas que abordó con una mirada fresca y un apasionado interés. Para ello, nos centraremos en cuatro aspectos de su producción intelectual e historiográfica: las biografías de funcionarios coloniales, las bibliotecas virreinales, la revolución de Independencia y el Perú republicano.

En lo que respecta al universo de las biografías, uno de los primeros objetos de estudio de Teodoro Hampe Martínez fue el análisis de la obra de don Pedro de La Gasca, conocido por la historiografía peruanista como "el pacificador", en gran medida debido a sus acciones en contra del levantamiento de Gonzalo Pizarro (1548). A él dedicó su tesis doctoral en la Universidad Complutense de Madrid: Don Pedro de La Gasca (1493-1567); su obra política en España y América (1986). De aquella investigación también nacie- ron dos importantes estudios dedicados a la labor política y jurídica del licenciado español: "Don Pedro de la Gasca y la proyección del mundo universitario salmantino en el siglo XVI" (1986) y "Don Pedro de la Gasca, Visitador general en el reino de Valencia (1542-1545)" (1987). Los aportes de estas primeras investigaciones redundaron en un conocimiento más acabado de la vida del licenciado en la península, entre su formación clerical en Alcalá de Henares y la de licenciado en Jurídica en la prestigiosa Universidad de Salamanca, contribuyendo a la comprensión de la ideología que subyacía a su proyecto político y a su desempeño como funcionario real en el proceso de pacificación del virreinato entre 1548 y 1551. Bajo la exégesis de Teodoro Hampe Martínez, la formación académica de La Gasca y sus servicios al emperador Carlos V definitivamente contribuyeron a la comprensión de sus actos una vez llegado al Perú, encaminados a imponer el predominio de los criterios políticos de la metrópoli. $Y$ es que la formación entregada por Francisco de Vitoria en Salamanca lo condujo a adoptar una posición intermedia entre los planteamientos radicales defendidos por eclesiásticos y burócratas que promovían, de una parte, una actitud tenazmente indiófila o, de otra, una agresivamente hispanizante. A fin de cuentas, el enfoque con que Teodoro Hampe Martínez abordó la figura de La Gasca aportó nuevos antecedentes que contribuyeron a superar la imagen que de él había construido la historiografía clásica, que redujo su actuación en el virreinato al escenario convulso de la rebelión pizarrista.

1 Centro de Estudios Históricos, Universidad Bernardo O’Higgins. Calle General Gana No 1702, Santiago de Chile.

Email: horrorflorido@gmail.com

2 Centro de Estudios Históricos, Universidad Bernardo O’Higgins. Calle General Gana No 1702, Santiago de Chile. Email: gmorongreyes@yahoo.es

3 Centro de Estudios Históricos, Universidad Bernardo O'Higgins. Calle General Gana No 1702, Santiago de Chile. Email: patricio.ibarra@ubo.cl 
Más adelante Teodoro Hampe Martínez centró su atención en la vida y obra del cronista oficial Agustín de Zárate, cuya biografía fue el motivo central de "Agustín de Zárate, contador y cronista indiano (Estudio biográfico)" (1991). En dicho trabajo, y siguiendo una tradición histórica y filológica de probada autoridad, su autor nos entregó un cuadro completo de la vida y obra del cronista vallisoletano. Importa destacar el hecho de que Hampe Martínez inscribió la labor de Zárate en el escenario de la profunda reorganización virreinal que comenzó con la aplicación tortuosa de las famosas Leyes Nuevas de 1542, las cuales determinaron su labor como funcionario encargado de poner orden al manejo fiscal de las colonias ultramarinas por allí por 1544 .

Como corolario a una larga dedicación al trabajo biográfico y monográfico, Teodoro Hampe Martínez escribió "El Licdo. Polo Ondegardo (ca. 1520-1575). Biografía de un jurista castellano en los Andes coloniales" (2012). Este artículo formó parte del libro Pensamiento colonial crítico, editado por Gonzalo Lamana y dedicado a compilar seis manuscritos fundamentales del licenciado Polo Ondegardo, reconocido funcionario colonial que dejaría a la postre un rico material antropológico e histórico sobre las costumbres, ritos y organización sociopolítica de las sociedades andinas en el siglo XVI. No debe sorprender que Lamana encargara a Teodoro Hampe Martínez el estudio biográfico de Ondegardo, quien elaboró un trabajo de impactante erudición, todo basado en documentación recogida previamente por destacados investigadores como Carlos Romero, Horacio Urteaga, Guillermo Lohmann y Laura González Pujana, dedicados a construir desde principios del siglo XX la semblanza del jurista español. La contribución precedente permitió observar con cuidado la multiplicidad de funciones y roles que ocuparon a Polo Ondegardo en su estadía en el Perú virreinal, entre ellos la de encomendero, jurista, visitador, corregidor de indios y comerciante, vinculando su figura -a nivel de parentesco- con la del cronista y contador Agustín de Zárate.

El principal aporte de las prolijas y exhaustivas biografías de Pedro de La Gasca, Agustín de Zárate y Polo Ondegardo fue que enriquecieron sustantivamente la visión sobre los contextos de producción en que se inscribieron sus textos, logrando dar cuenta de las circunstancias por las cuales cada uno de ellos se alineó o fue refractario a las políticas virreinales impuestas desde la metrópoli. Al mismo tiempo, estas contribuyeron a contextualizar históricamente sus ideologías, sus necesidades y sus proyectos personales e institucionales, sobre todo en la etapa peregrina del desarrollo de la historia del Perú colonial (15321600), territorio de un escenario tristemente célebre por el desorden y los levantamientos anti-fiscales.

En forma paralela a los estudios biográficos, y respondiendo a los múltiples intereses que poseía, Teodoro Hampe Martínez comenzó a destacarse por sus investigaciones en torno a las bibliotecas virreinales. No habiendo cumplido aún los treinta años, publicó "Lecturas de un jurista del siglo XVI" (1984), en donde ahondó en el examen de la biblioteca del Doctor Gregorio González de La Cuenca, quien ocupó importantes cargos administrativos en las audiencias de Lima y Santo Domingo. Pionero en el tema, junto con Pedro Guibovich Pérez, este trabajo se transformaría en el primero de una serie de publicaciones centradas en la composición y análisis de las bibliotecas virreinales, tema que Teodoro Hampe Martínez abordó de la mano de Maxime Chevalier, Marcel Bataillon, José Durand y José Torre Revello, entre otros. Siguieron a este artículo "La biblioteca del virrey don Martín Enríquez. Aficiones intelectuales de un gobernante colonial" (1986) y "La biblioteca del Arzobispo Hernando Arias de Ugarte. Bagaje intelectual de un prelado criollo" (1987).

Dando un paso más allá, y cuatro años más tarde, Teodoro Hampe Martínez publicó "Lexicografía y cultura. Diccionarios de lenguas europeas e indígenas en las bibliotecas del Perú colonial (Siglos XVI- XVII)" (1991), artículo elaborado en base a un corpus documental mucho más extenso, fruto de la búsqueda y sistematización de diversas fuentes tanto éditas como inéditas. Haciendo uso del mordaz humor que caracterizó su pluma, allí abordó las empresas de traducción desde una perspectiva crítica que oponía los diccionarios latinos a los vernáculos y los indígenas, en tanto los primeros eran considerados superiores a los segundos. Por ello, las aglomeraciones de términos y citas de obras clásicas que caracterizaron estos vocabularios, según nuestro autor siguiendo a Georges Matoré, habrían sido cómplices del primado de la "erudición más indigesta y la pedantería más ostentosa" que caracterizó el Humanismo, al mismo tiempo que se transformaron en la principal fuente de sabiduría para el público citadino y menos instruido. 
En la misma línea del trabajo anterior se encuentra "El eco de los ingenios: literatura española del siglo de oro en las bibliotecas y librerías del Perú colonial" (1992), en donde Teodoro Hampe Martínez analizó el flujo y la influencia que las obras más populares del Siglo de Oro ejercieron en la mentalidad y actividad creadora de los lectores hispanoamericanos. De paso, advertía que el impacto de la cultura libresca en el virreinato del Perú era un campo aun poco explorado entre los investigadores, dada la tarea ingente que implicaba poseer conocimientos en casi todos los ramos del saber. En consecuencia, era indispensable contar con un equipo que trabajara "en calibrar a fondo las influencias de los autores, corrientes ideológicas y avances científicos en la producción intelectual del Nuevo Mundo". El acento en las proyecciones de las bibliotecas virreinales como tema de investigación también está presente en "The diffusion of books and ideas in colonial Peru: a study of private libraries in the sixteenth and seventeenth centuries" (1993), en donde Teodoro Hampe Martínez evidenció la necesidad de contar con un enfoque multidisciplinario en el análisis de la cultura libresca de los siglos XVI y XVII advirtiendo, junto con ello, las limitantes que los inventarios presentaban a la hora de determinar el efecto que realmente estos libros habían tenido entre sus lectores.

Habiendo transcurrido ya diez años desde sus primeras incursiones en las bibliotecas virreinales, Teodoro Hampe Martínez publicó en 1996 Bibliotecas privadas en el mundo colonial. La difusión de libros e ideas en el virreinato del Perú (siglos $X V I-X V I I)$, libro que compiló y sintetizó sus trabajos previos sobre el tema. El mismo año vio la luz Cultura barroca y extirpación de idolatrías. La biblioteca de Francisco de Ávila-1648, en donde analizó el inmenso universo de lecturas que rodeó la vida del célebre extirpador.

Con el correr de los años, los intereses de Teodoro Hampe Martínez se diversificaron, aunque no por eso abandonó las bibliotecas virreinales. Como él mismo lo dijera a propósito del inventario de la biblioteca de Don Francisco de Toledo en "Las bibliotecas virreinales en el Perú y la difusión del saber italiano: el caso del virrey Toledo (1582)" (2008), los gustos y referentes intelectuales y literarios de una persona cambian conforme se desarrolla su vida. Por ende, el registro de sus libros al filo de la muerte solo revelará sus lecturas en ese momento, más aún si se trata de personas que viajaron mucho, como una buena parte de los funcionarios virreinales que poseyeron bibliotecas.
Que los gustos y referentes literarios cambian a lo largo de la vida de una persona es una máxima que también puede aplicarse a la vida del mismo Teodoro Hampe Martínez: ya en Bibliotecas, imprentas y difusión de noticias en el Perú colonial (2011) el autor dejó entrever su interés por el funcionamiento de la prensa en el periodo colonial en vísperas de la Emancipación, la revolución de la Independencia y otros temas del siglo XIX peruano. Su muerte dejó trunco este periplo que había decidido iniciar, dispuesto a innovar en temas más contemporáneos.

Ejemplo de su interés por el siglo XIX son los artículos, recensiones de libros y ponencias en congresos de la especialidad en materias tan disímiles como la Constitución de Cádiz de 1812 y su influencia en el espacio peruano, la conformación de la burocracia estatal del Perú republicano, el trabajo de los empresarios Henry Meiggs y Miguel Grace en la construcción del ferrocarril andino y el estudio de la figura del almirante Miguel Grau, entre otras publicaciones. Pese a la diversidad de temas, estos escritos siempre descansaron en una sólida base documental y bibliográfica.

Su interés por las formas que adquirió la administración del Estado peruano, en la transición del Antiguo Régimen monárquico hacia la República de rasgos liberales en los veinte años que transcurrieron entre 1810 y 1830 , se plasmó en la investigación llevada adelante en conjunto con José Félix Gálvez intitulada "De la intendencia al Departamento, 1810- 1830. Los cambios en la administración pública regional del Perú" (2000). Allí, analizó y describió el proceso de cambio y continuidad en la configuración burocrática de siete intendencias, que luego de afianzada la Independencia del Perú sirvieron de base para la implementación de los departamentos, denominación que adquirieron estas unidades administrativas al momento de iniciar la construcción del Estado Nacional decimonónico.

Como se señaló anteriormente, el interés de Hampe Martínez por el estudio de la primera parte del siglo XIX también se manifestó en lo referido a la influencia en el Perú de las Cortes de Cádiz, que asumieron la soberanía española ante la invasión napoleónica y la captura de Fernando VII en 1810, y la Constitución de 1812, una de sus herencias más notables. En primer término, se encuentra el artículo "La "primavera" de Cádiz: libertad de expresión y opinión pública en el Perú (1810-1815)” (2012), donde asumió el 
desafío de examinar el impacto del decreto de la libertad de imprenta de noviembre de 1810, uno de los derechos esenciales en el ideario liberal, que trajo como consecuencia que se produjera un debate político inédito hasta ese momento en la Ciudad de los Reyes. Este se sustentó en la circulación de varios periódicos, folletos, manifiestos y numerosas hojas sueltas donde se colocaron a disposición del público letrado algunos de los planteamientos políticodoctrinarios claves del liberalismo del siglo XIX. De la misma manera, en "Sobre la Constitución de 1812: Las cortes gaditanas y su impacto en el Perú" (2012), se dio la tarea de estudiar la representación peruana en las Cortes de Cádiz, además de esbozar la influencia decisiva que tuvo la Constitución de 1810 en las formas ideológicas y políticoconstitucionales en la revolución de la Independencia en Hispanoamérica. En esa misma línea se encuentra la recensión del libro de V. H. Chanduvi y J. Gálvez Las Cortes de Cádiz y su aporte al constitucionalismo peruano (2009) y la ponencia "Orígenes del constitucionalismo Hispanoamericano" presentada en el marco del encuentro "Las Cortes de Cádiz en su Bicentenario", evento coordinado por el propio Teodoro Hampe Martínez y realizado en el Centro Cultural de España (Lima) los días 14 y 15 de marzo de 2012. Allí subrayó la importancia de "La Pepa", como se nombró coloquialmente a la Constitución de 1812, en el desarrollo y consolidación de las instituciones republicano- liberales en América Latina, durante la época de la creación del Estado Nacional. Los estudios mencionados se enmarcan en la corriente revisionista de los procesos políticos latinoamericanos, la cual permitió dar una nueva mirada a temas largamente tratados por los historiadores clásicos de fines del siglo XIX y comienzos del XX, esta vez de la mano del impulso dado a estos a partir de la década de 1990 por Francois Xavier Guerra, Antonio Annino o Hilda Sabato, entre otros inquisidores del pasado.

Una de las propuestas interpretativas más interesantes de Teodoro Hampe Martínez, relacionadas con la Independencia del Perú, fue su idea de que el verdadero hito para la celebración del bicentenario era la fallida "revolución del Cusco" del 3 de agosto de 1814. En esa oportunidad, las ciudades de Arequipa, Cusco y Huamanga se rebelaron contra la autoridad central monárquica debido a su negativa de aplicar en plenitud las disposiciones electorales contempladas en la Constitución de Cádiz. Pese al fracaso de la revuelta, provocado por el alejamiento de su cúpula debido a la radicalización de los indígenas y los actos de violencia de mestizos y criollos, esta se constituyó en un referente que, en la óptica de nuestro autor, debía ser recuperado y realzado en función a su importancia simbólica, sobre todo por el cariz multiétnico del movimiento dentro del proceso de la lucha por la emancipación peruana (2014). En la misma línea se encuentra su propuesta de adelantar la celebración de la Independencia peruana del 28 al 15 de julio, día en el cual el vecindario de Lima se declaró a favor de la Independencia del Perú.

Así también, Teodoro Hampe Martínez exploró temas de la segunda mitad del siglo XIX como, por ejemplo, una de las empresas de obras públicas más ambiciosas del Perú decimonónico: la construcción del tren a la Sierra andina. En "Meiggs, Grace y la obra del ferrocarril central andino (1870-1885)" (2010), estudió el derrotero del trabajo del ingeniero Henry Meiggs y sus colaboradores, marcado por la muerte del propio Meiggs en 1877, la derrota del Perú en la Guerra del Pacífico (1879-1883) y la entrada al proyecto del empresario Miguel Pablo Grace, quien logró finalizar las faenas.

De la misma manera, destaca el libro Miguel Grau. Protagonista político (2013) donde trató al connotado marino no en su rol como comandante del monitor Huáscar durante la Guerra del Pacífico, sino como servidor público en la condición de representante por Piura en el Congreso de la República del Perú entre 1875 y 1879, innovando de ese modo en el estudio de uno de los máximos referentes del panteón heroico del Perú republicano.

Junto con su interés en la historia del Perú, Teodoro Hampe Martínez en varias oportunidades escribió ensayos biográficos u obituarios centrados en las vidas de quienes habían orientado sus pasos en el camino de la Historia. En "Guillermo Lohmann Villena (1915-2005): un gigante de la historiografía americanista" (2005), por ejemplo, rescató la inmensa producción académica del historiador limeño, vinculada en gran medida a la historia institucional y del derecho, la genealogía, la historia de la literatura, el análisis de los grupos sociales y el estudio del comercio y la producción, entre otros. Del mismo modo, en "Ruggiero Romano (1923-2002), gran maestro de la historia económica" (2001), se adentró en la obra del intelectual italiano quien, desde la escuela estructuralista, se dedicó al estudio de la estrecha relación económica que la América española tuvo con el Viejo Mundo. En esa misma oportu- 
nidad, Hampe Martínez se refirió a la relación de amistad personal que mantuvo con Romano, materializada en un intercambio epistolar entre ambos. Esas cartas, confesó, eran de las "más dilectas de mi archivo particular". Por último, en "José Durand, bibliófilo: su colección de libros y papeles en la Universidad de Notre Dame" (1997), relevó la gran pasión que este tenía por la obra del Inca Garcilaso, situándola en la perspectiva del Renacimiento y el Barroco y dejando de lado las "fantasiosas elucubraciones" que habían rodeado su figura. Recordamos a Teodoro Hampe
Martínez, con sus dos apellidos -tal como le gustaba-, con el mismo entusiasmo con que él homenajeó a quienes influyeron y determinaron su carrera académica, como un bibliófilo que -con curiosidad- escudriñaba en las bibliotecas de otros bibliófilos, como un historiador moderno con la impronta de los clásicos. Su inesperado fallecimiento dejó a medio camino una promisoria colaboración con nosotros, la cual apenas comenzaba: quedaron pendientes la edición de un libro sobre Henrique Urbano y un café en Santiago.

\section{$*$ Referencias citadas}

\section{HAMPE MARTÍNEZ, T.}

1984. Lecturas de un jurista del siglo XVI. Anuario de Estudios Americanos 41: 143-193.

1986. Don Pedro de La Gasca (1493-1567); su obra política en España y América. Tesis para optar al grado de Doctor en Historia. Universidad Complutense de Madrid, España.

1986. Don Pedro de la Gasca y la proyección del mundo universitario salmantino en el siglo XVI. Mélanges de la Casa de Velázquez 22:171195.

1986. La biblioteca del virrey don Martín Enríquez. Aficiones intelectuales de un gobernante colonial. Historia Mexicana 36(2): 251271.

1987. Don Pedro de La Gasca, Visitador general en el reino de Valencia (1542-1545). Estudis: Revista de Historia Moderna 89(1-4): 55-84.

1987. La biblioteca del Arzobispo Hernando Arias de Ugarte. Bagaje intelectual de un prelado criollo. Thesaurus XLII(2): 337-361.

1991. Agustín de Zárate, contador y cronista indiano (Estudio biográfico). Mélanges de la Casa de Velázquez 27(2): 129-154.

1991. Lexicografía y cultura. Diccionarios de lenguas europeas e indígenas en las bibliotecas del Perú colonial (Siglos XVI- XVII). Thesaurus XLVI(1): 17-42.

1992. El eco de los ingenios: literatura española del siglo de oro en las bibliotecas y librerías del Perú colonial. Histórica XVI(2): 177201.

1993. The diffusion of books and ideas in colonial Peru: a study of private libraries in the sixteenth and seventeenth centuries. The Hispanic American Historical Review 73(2): 211- 233.
1996. Bibliotecas privadas en el mundo colonial. La difusión de libros e ideas en el virreinato del Perú (siglos XVI-XVII). Iberoamericana, Madrid.

1996. Cultura barroca y extirpación de idolatrías. La biblioteca de Francisco de Ávila- 1648. Centro de Estudios Regionales Andinos Bartolomé de Las Casas, Perú.

1997. José Durand, bibliófilo: su colección de libros y papeles en la Universidad de Notre Dame. Revista de Indias LVII(210): 541- 562.

2000. (En coautoría con José Félix Gálvez) De la intendencia al Departamento, 1810-1830. Los cambios en la administración pública regional del Perú. En Dinámicas de Antiguo Régimen y orden constitucional. Representación, justicia y administración en Iberoamérica. Siglos XVIII -XIX, Bellingeri, M. (ed.), pp. 339-366. Otto Editore, Turín.

2001. Ruggiero Romano (1923- 2002), gran maestro de la historia económica. Histórica 25 (2): 225 - 234.

2005. Guillermo Lohmann Villena (1915-2005): un gigante de la historiografía americanista. Historia Mexicana LV(2): 673- 687.

2008. Las bibliotecas virreinales en el Perú y la difusión del saber italiano: el caso del virrey Toledo (1582). En Las cortes virreinales de la Monarquía española, F. Cantú (ed.), pp. 537-554. Università di Roma Tre, Roma.

2009. Las Cortes de Cádiz y su irradiación constitucional en el Perú. Recensión del libro Las Cortes de Cádizy su aporte al constitucionalismo peruano de Chanduví, V. y Gálvez, J. En Historia Constitucional 10: 507-509.

2010. Meiggs, Grace y la obra del ferrocarril central andino (18701885). Historia 9: 83-94.

2011. Bibliotecas, imprentas y difusión de noticias en el Perú colonial. Bulletin hispanique 113(1): 409- 432 . 
2012. La "primavera" de Cádiz: libertad de expresión y opinión pública en el Perú (1810-1815). Historia Constitucional 13: 339-359.

2012. Orígenes del constitucionalismo hispanoamericano. Historia Constitucional 13: 791- 794 .

2012. Sobre la Constitución de 1812: Las cortes gaditanas y su impacto en el Perú. Trocadero 24: 27-36.
2012. "El Licdo. Polo Ondegardo (ca. 1520-1575). Biografía de un jurista castellano en los Andes coloniales". En Pensamiento colonial crítico. Textos y actos de Polo Ondegardo, Lamana, G. (ed.), pp. 89-128. IFEA-CBC, Lima/ Cusco.

2013. Miguel Grau. Protagonista político. Municipalidad Provincial de Piura, Piura.

2014. La rebelión del Cusco. El Comercio. 07/ 08/ 2014. Lima. 